\title{
Aerosol classification from airborne HSRL and comparisons with the CALIPSO vertical feature mask
}

\author{
S. P. Burton, R. A. Ferrare, M. A. Vaughan, A. H. Omar, R. R. Rogers, C. A. Hostetler, and J. W. Hair \\ NASA Langley Research Center, MS 401A, Hampton, VA, 23681, USA \\ Correspondence to: S. P. Burton (sharon.p.burton@nasa.gov)
}

Received: 10 January 2013 - Published in Atmos. Meas. Tech. Discuss.: 14 February 2013

Revised: 19 April 2013 - Accepted: 29 April 2013 - Published: 23 May 2013

\begin{abstract}
Aerosol classification products from the NASA Langley Research Center (LaRC) airborne High Spectral Resolution Lidar (HSRL-1) on the NASA B200 aircraft are compared with coincident V3.01 aerosol classification products from the Cloud-Aerosol Lidar with Orthogonal Polarization (CALIOP) instrument on the CALIPSO satellite. For CALIOP, aerosol classification is a key input to the aerosol retrieval, and must be inferred using aerosol loadingdependent observations and location information. In contrast, HSRL-1 makes direct measurements of aerosol intensive properties, including the lidar ratio, that provide information on aerosol type. In this study, comparisons are made for 109 underflights of the CALIOP orbit track. We find that $62 \%$ of the CALIOP marine layers and $54 \%$ of the polluted continental layers agree with HSRL-1 classification results. In addition, $80 \%$ of the CALIOP desert dust layers are classified as either dust or dusty mix by HSRL-1. However, agreement is less for CALIOP smoke $(13 \%)$ and polluted dust $(35 \%)$ layers. Specific case studies are examined, giving insight into the performance of the CALIOP aerosol type algorithm. In particular, we find that the CALIOP polluted dust type is overused due to an attenuation-related depolarization bias. Furthermore, the polluted dust type frequently includes mixtures of dust plus marine aerosol. Finally, we find that CALIOP's identification of internal boundaries between different aerosol types in contact with each other frequently do not reflect the actual transitions between aerosol types accurately. Based on these findings, we give recommendations which may help to improve the CALIOP aerosol type algorithms
\end{abstract}

\section{Introduction}

An aerosol classification scheme was introduced by Burton et al. (2012) for airborne High Spectral Resolution Lidar (HSRL) measurements from the NASA Langley HSRL-1 instrument. A qualitative classification of aerosol type along with the quantitative profile measurements of aerosol backscatter and extinction provided by the airborne HSRL-1 has many useful applications. HSRL-1 aerosol classification results have been used to support and interpret coincident aircraft in situ and satellite measurements made by other research groups (Molina et al., 2010; Warneke et al., 2010; Ottaviani et al., 2012; Zaveri et al., 2012; Patadia et al., 2013). In addition, the products can be used to apportion aerosol optical thickness (AOT) by type and vertical location in the column. In contrast, it is not possible to resolve scenes with layers of multiple types using passive imaging radiometer or polarimeter measurements. This kind of information is useful for estimating radiative forcing throughout the column and understanding aerosol lifetime and transport. It is also useful for assessing the predictions of transport models (de Foy et al., 2011), i.e., determining whether the models predict the correct aerosol type at the correct altitude. Knowledge of aerosol type is also important for air quality applications.

The Cloud-Aerosol Lidar with Orthogonal Polarization (CALIOP) lidar instrument (Winker et al., 2009) aboard the Cloud-Aerosol Lidar and Infrared Pathfinder Satellite Observations (CALIPSO) satellite has already provided the first long-term global data set of aerosol vertical distribution, which has proven valuable for assimilation into global aerosol transport models (Zhang et al., 2011; Campbell et al., 2010) and for model assessment (e.g., Ford and Heald, 2012; Yu et al., 2010; Koffi et al., 2012). Aerosol classification 
(Omar et al., 2009) is vital to accurate aerosol extinction and AOT retrievals from CALIOP since the retrieval of aerosol extinction and backscatter from this instrument requires an inference of the lidar ratio (the ratio of aerosol extinction to backscatter), and for most detected aerosol layers, the lidar ratio is assigned using the inferred aerosol type. Errors in the CALIOP aerosol layer extinction product can largely be attributed to either mistyping of aerosol layers or errors in the modeled lidar ratios for particular types (Rogers et al., 2013). In addition, the CALIOP aerosol classification results are used directly by researchers to support identification of aerosol airmasses of specific type (e.g., Ottaviani et al., 2012; Yang et al., 2012; Vadrevu et al., 2012; Sun et al., 2013). However, concerns about the limitations of the aerosol typing have been raised by some researchers. Ford and Heald (2012) point out that the location and layer elevation criteria in the CALIOP selection algorithm may be too limiting; specifically, that smoke can only be identified in elevated layers and that elevated layers over the ocean cannot be classified as polluted continental aerosol. Campbell et al. (2012) find discontinuities at coastlines due to the fact that the algorithm's options for aerosol types differ over land and ocean. Schuster et al. (2012) point out that some aerosol layers in coastal regions that are classified as clean marine may be "misclassified" in the sense that they are also affected by outflow of continental pollution. A similar conclusion is drawn by Oo and Holz (2011) who demonstrate underestimation of AOT in some marine areas in which CALIOP identifies clean marine, but the fine mode fraction from the Moderate Resolution Imaging Spectroradiometer (MODIS) suggests a mixture of fine and coarse aerosols. In addition, they point out higher fine mode fractions in polluted dust cases than what would be expected based on the CALIOP aerosol type models. An attempt to validate the CALIOP v2.01 aerosol typing by comparison with the AErosol RObotic NETwork (AERONET) was performed by Mielonen et al. (2009). They derived five aerosol subtypes from AERONET measurements of single scattering albedo and Angstrom exponent, and found agreement in $63 \%$ of the cases between the most common subtype from CALIOP with the most common subtype from AERONET, on a day-by-day basis. The greatest agreement was for the dust type $(91 \%)$ with moderate agreement for the polluted dust type (53\%) and poorer agreement for biomass burning (37\%) and for polluted and clean continental combined $(22 \%)$.

Oo and Holz (2011) point out that a primary difficulty for the CALIOP lidar ratio selection algorithm is that the selection criteria do not include properties such as aerosol particle size that are directly linked to lidar ratio. The CALIOP lidar ratio selection algorithm must rely on loadingdependent lidar measurements and information that is only indirectly related to aerosol type, rather than on aerosol intensive properties. Aerosol intensive properties are those which are loading-independent; these properties give important information about aerosol type. The only intensive aerosol property that can be used in the CALIOP aerosol type selection is an approximate particle depolarization ratio (see Eq. 10 of Omar et al., 2009), but even this estimate is affected by attenuation that depends on the aerosol loading, since the aerosol type selection algorithm occurs before the extinction retrieval (This will be discussed further in Sect. 4.5). The airborne HSRL-1 provides unambiguous retrievals of four intensive properties that give information about aerosol type, including the lidar ratio itself. The CALIOP inference of aerosol type and assignment of lidar ratio play a critical role in the subsequent calculation of aerosol extinction and optical depth. Therefore an assessment of the performance of the CALIOP aerosol classification in comparison to the NASA airborne HSRL-1 classification is valuable. Since 2006, the NASA Langley HSRL-1 has routinely provided data for validating CALIOP. In this work, we make a detailed comparison of the aerosol types that are used in the CALIOP retrieval (Omar et al., 2009) with those derived from HSRL-1 measurements, for 109 flights of HSRL-1 along the CALIPSO ground track. After a brief description of the HSRL-1 and CALIOP instruments in the next section and a discussion of the aerosol types that are represented in the two aerosol classification schemes in Sect. 3, we describe the comparison of aerosol classification results in Sect. 4, including overall statistics for the 109 flights and four case studies that highlight specific findings. In Sect. 5, we discuss a "hybrid" HSRL-CALIOP experiment where we use the HSRL-1 measurements together with the CALIOP retrieval programs to gain further insight into the comparisons. Finally, in Sect. 6, we discuss recommendations for improving the aerosol typing from CALIOP and summarize our findings.

\section{Instrument descriptions}

The CALIPSO satellite was launched 28 April 2006 in formation with the Aqua and CloudSat satellites and is in its 8th year of operation. The primary instrument on board is the CALIOP sensor, the first satellite lidar optimized for cloud and aerosol observations (Winker et al., 2007). It provides measurements of attenuated backscattered signal at two wavelengths, $1064 \mathrm{~nm}$ and $532 \mathrm{~nm}$, and depolarization at $532 \mathrm{~nm}$. The vertical resolution of the Level 1 attenuated backscattering data is $30 \mathrm{~m}$ below $8.2 \mathrm{~km}$, and data are provided approximately every $0.05 \mathrm{~s}$ or $1 / 3 \mathrm{~km}$ horizontally. Above $8.2 \mathrm{~km}$, both the horizontal and vertical resolution are less (Hunt et al., 2009). The horizontal averaging for the CALIOP aerosol products is described by Young and Vaughan (2009). The Version 3.01 products are reported on a nominal $5 \mathrm{~km}$ horizontal grid; the vertical resolution is $60 \mathrm{~m}$ between the surface and $20.2 \mathrm{~km}$ and $180 \mathrm{~m}$ above that altitude (Powell et al., 2011).

The operational algorithms for the aerosol-cloud discrimination, aerosol classification and extinction retrieval are described by Liu et al. (2009), Omar et al. (2009), and Young 
and Vaughan (2009), respectively. In these algorithms, layers are detected using a multi-resolution spatial averaging scheme as described by Vaughan et al. (2009). Aerosol layers are assigned to one of six aerosol types (desert dust, biomass burning, clean continental, polluted continental, marine, and polluted dust) each having a characteristic lidar ratio. As described by Omar et al. (2009), aerosol models, including lidar ratios, for the six aerosol types were derived from field measurements and AERONET (Holben et al., 1998) retrievals. The dust and polluted dust categories were updated for V3.01 using dust measurements from the NASA African Monsoon Multidisciplinary Analyses (NAMMA) field campaign and T-Matrix calculations of particle phase functions (Omar et al., 2010). The CALIOP retrieval categorizes observed layers among the six types using a decision tree which takes into account the optical measurements (approximate particle depolarization and attenuated backscatter) and aerosol location, height, and surface type. The goal of this part of the CALIOP algorithm is to determine the lidar ratio to an uncertainty of no more than $30 \%$.

HSRL-1 (Hair et al., 2008) is the first airborne High Spectral Resolution Lidar instrument built and operated by NASA Langley (A follow-on instrument, HSRL-2, with additional HSRL capability at $355 \mathrm{~nm}$, flew on its first field mission in July 2012). It uses the HSRL technique to independently retrieve aerosol and tenuous cloud extinction and backscatter (Grund and Eloranta, 1991; She et al., 1992; Shipley et al., 1983) without a priori information on aerosol type or extinction-to-backscatter ratio, as is required for standard elastic backscatter lidar retrievals. The LaRC HSRL-1 employs the HSRL technique at $532 \mathrm{~nm}$ and the standard backscatter technique at $1064 \mathrm{~nm}$. It also measures depolarization at both wavelengths. The instrument is internally calibrated at $532 \mathrm{~nm}$ for measurements of aerosol/cloud backscatter and extinction, and at both 532 and $1064 \mathrm{~nm}$ for measurements of depolarization. The $1064 \mathrm{~nm}$ backscatter calibration makes use of the $532 \mathrm{~nm}$ calibration and, therefore, also avoids the necessity of assuming clear air in the calibration region. This combination of measurements and calibration procedures enables direct and unambiguous retrieval of loading-invariant aerosol intensive properties in addition to loading-dependent extensive properties. The intensive properties provided by HSRL-1 are the $532 \mathrm{~nm} \mathrm{li-}$ dar ratio, the aerosol depolarization ratios at both $532 \mathrm{~nm}$ and $1064 \mathrm{~nm}$, and the backscatter color ratio (i.e., the ratio of aerosol backscatter coefficients at the two wavelengths; note that the $1064 \mathrm{~nm}$ value depends on a nominal lidar ratio which produces an error of no more than $15 \%$ due to limited sensitivity of backscatter to the lidar ratio assumption at $1064 \mathrm{~nm}$ ). The intensive parameters provide information about the aerosol physical properties and are combined to infer aerosol type. The HSRL-1 classification is performed using a semi-supervised method based on labeled samples comprising $0.3 \%$ of the HSRL- 1 measurement database. The labeled samples are cases where external information (e.g., in
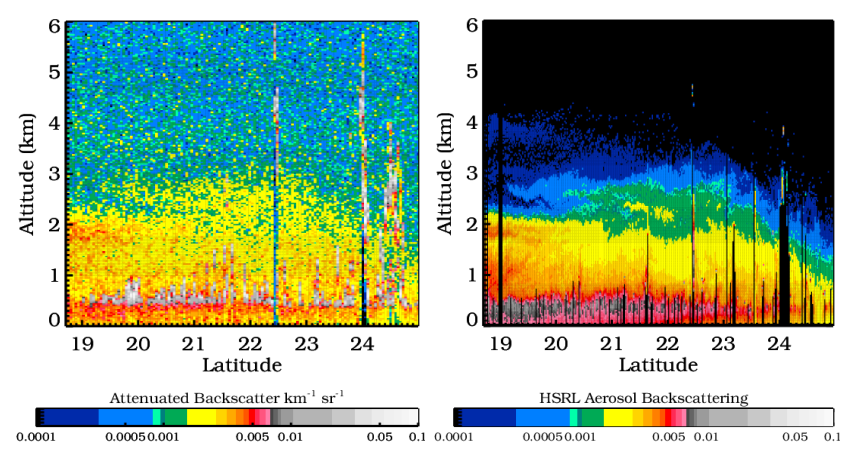

Fig. 1. Total attenuated backscatter at $532 \mathrm{~nm}$ measured by CALIOP is shown (left panel) for a portion of a nighttime scene in the Caribbean Sea on 24 August 2010 which includes advected Saharan dust. The CALIPSO satellite transited this scene in $1.7 \mathrm{~min}$. The data includes $5 \mathrm{~km}$ horizontal smoothing, similar to online browse images available at http://eosweb.larc.nasa.gov/PRODOCS/calipso/ table_calipso.html through the NASA Langley Atmospheric Science Data Center. Also shown (right) is the aerosol backscatter coefficient at $532 \mathrm{~nm}$ for the same scene as measured by the LaRC airborne HSRL-1 instrument on a coincident underflight. The transit time for the B200 with HSRL aboard was $101 \mathrm{~min}$.

situ measurements, back-trajectory analysis, and visual identification of plumes from the aircraft) has been used to determine the aerosol type. Observations in the remainder of the dataset are then classified by comparison with the labeled samples using the Mahalanobis distance metric. This two-stage method allows the detailed external information for a limited number of cases to be leveraged for use in classifying all other cases where the type is unknown (Burton et al., 2012). The aerosol classification for the current study is performed on a measurement-by-measurement basis after smoothing the measured intensive parameters over one minute horizontally (about $6 \mathrm{~km}$ ) and nine $30 \mathrm{~m}$ bins vertically.

Figure 1 shows coincident backscatter measurements at $532 \mathrm{~nm}$ made by CALIOP and HSRL- 1 for a nighttime scene, illustrating some of the differences between the two measurement systems that are relevant to the aerosol type classification. The HSRL technique allows for the direct and unambiguous retrieval of (unattenuated) aerosol backscatter and extinction coefficients (backscatter shown). The ratio of the two (the lidar ratio) is one factor used to infer aerosol type as an additional product. On the other hand, the CALIOP direct measurement is a measurement of attenuated aerosol backscatter coefficient; the retrieval of aerosol backscatter and extinction coefficients requires an inference of the lidar ratio which in most cases relies on an assessment of aerosol type which, therefore, must be made early in the retrieval process using only a relatively limited set of information. Furthermore, the relatively large amount of noise in the CALIOP measurements demands a layer detection step prior to the aerosol retrieval to allow for averaging within discrete 
aerosol layers. In contrast, the HSRL aerosol retrieval is done with minimal averaging and includes no explicit layer detection.

Between March 2006 and March 2012, the airborne HSRL-1 has flown more than $1200 \mathrm{~h}$ during 349 science flights on the NASA King Air B200 on nineteen field campaigns across North America, including process-oriented field projects for NASA, the Department of Energy, and the Environmental Protection Agency, and field projects devoted to CALIPSO satellite validation. The HSRL-1 has been extensively validated against in situ and remote-sensing measurements, as described by Rogers et al. (2009), in which the HSRL-1 AOT product was shown to be within $6 \%$ of measurements from well-established sensors (i.e., the NASA Ames Airborne Sun Photometer (AATS-14) (Redemann et al., 2009) and the Hawaii Group for Environmental Aerosol Research (HiGEAR) (McNaughton et al., 2009) suite of instruments). As a primary validation instrument for the CALIOP lidar (Powell et al., 2009), the airborne HSRL-1 has flown 109 successful validation flights for the CALIPSO program and has provided a unique dataset crucial for validating both level 1 (Rogers et al., 2011) and level 2 (Rogers et al., 2013) CALIOP data products and represents the most accurate and comprehensive dataset available for comparison with CALIOP (Winker et al., 2012).

\section{Aerosol types}

Due to various differences in both the methodology and motivation for the aerosol type classifications, the CALIOP and HSRL schemes do not completely overlap in the set of types used. Here we provide a brief description of the aerosol types identified in the two datasets.

\subsection{HSRL-1 aerosol classes}

The HSRL-1 aerosol classification consists of eight types, shown in Table 1, described in detail by Burton et al. (2012), based on samples of known type observed on airborne field missions in North America since 2006. These are ice, pure dust, dusty mix, maritime, polluted maritime, urban, smoke and fresh smoke. The first of these, ice, is not strictly an aerosol type, but neither is it meant as a cloud type discriminator. It is most relevant to the April 2008 Arctic Research of the Composition of the Troposphere from Aircraft and Satellites (ARCTAS) field mission in Alaska where HSRL-1 observed extensive cases of optically thin ice crystal haze at altitudes below the aircraft. These are probably best described as Altostratus nebulosus, a classification introduced by Sassen and Wang (2012). Some instruments, including total sky imagers and AERONET, indicated clear sky in these cases and, therefore, the optical depth from these ice crystals are included in AERONET aerosol totals. In addition, they are not easily cleared using the typical HSRL-1 cloud-clearing algorithm. Therefore, there is sufficient motivation to identify these cases in the aerosol classification scheme. However, the ice aerosol type is not relevant to comparisons between HSRL-1 and CALIOP, since it is not present in a significant number of the coincident observations. There is no corresponding aerosol type in the CALIOP aerosol classification algorithm.

Although all four HSRL-1 intensive variables are used simultaneously in the aerosol classification, dust and dusty mix (as well as the ice type) are primarily distinguished from other types by the aerosol depolarization ratio (also called particle depolarization ratio), which is an indicator of nonspherical particles. Pure dust is characterized by aerosol depolarization of approximately 30-35\% (e.g., Shimizu et al., 2004; Freudenthaler et al., 2009) and in the HSRL-1 record is primarily African or Asian dust advected away from the source, but remaining unmixed enough to still exhibit this high degree of aerosol depolarization. Other cases from different sources with this degree of depolarization exist in the HSRL-1 record and are also classified as pure dust, including cases of wind-blown dust on the slopes of the Pico de Orizaba near Mexico City (Burton et al., 2012). The dusty mix type exhibits an intermediate amount of aerosol depolarization, between about $10 \%$ and $30 \%$. Observations of intermediate depolarization are frequently assumed to reflect a mixture of pure dust with other aerosol types (e.g., Sugimoto and Lee, 2006; Tesche et al., 2009; Gasteiger et al., 2011; Groß et al., 2011). Observations of dust from other sources (such as wind-blown road dust) occur in this category and are likewise assumed to be a mixture, but published measurements of such cases do not exclude the possibility of other types of pure dust having depolarization much less than the more frequently studied Saharan dust. Such cases would be subsumed into the dusty mix category in the HSRL-1 classification, since the depolarization is the primary discriminator for this type. The depolarization dominates the optical properties in HSRL-1 observations of dust and dust mixtures, and no attempt is made to automatically distinguish the nondepolarizing type in a dust mixture in the current version of the aerosol classification, so the dusty mix class in practice includes not only cases of dust mixed with pollution aerosol, but also cases of dust mixed with marine aerosol.

Maritime aerosol is distinguished in the HSRL-1 record primarily by its low lidar ratio, low aerosol depolarization values, indicating spherical particles, and small backscatter color ratio, indicating relatively large particles. Unsurprisingly, it is found mainly over water in the HSRL-1 record, but can also be found over land in some cases, where local meteorology causes the marine air to be blown inland. The polluted maritime aerosol type can also be found in coastal regions and has optical properties intermediate between marine air and urban pollution and is inferred to be a mixture of marine and pollution aerosols.

Both the urban and smoke classes are distinguished from other aerosol types by their high lidar ratio (43-87 sr), low 
aerosol depolarization, and large backscatter color ratio, indicating small, spherical, absorbing particles. They are distinguished from each other in the HSRL-1 classification scheme primarily by the spectral depolarization ratio, which was found empirically to distinguish the two types in a number of measurement samples (Burton et al., 2012). However, the spectral depolarization ratio is not a perfect discriminator of the two types and they remain difficult to separate. We expect to achieve more accurate discrimination between smoke and urban aerosol from the newer HSRL2 instrument (see http://fallmeeting.agu.org/2012/files/2012/ 12/A13K-0336_Hostetler_et_al.pdf) that uses the HSRL technique at both $532 \mathrm{~nm}$ and $355 \mathrm{~nm}$, since the wavelength dependence of the lidar ratio has been shown to be useful for separating pollution from smoke (Müller et al., 2007). For the HSRL-1 classification results discussed here, the smoke type primarily indicates cases of lofted and advected smoke that has traveled over several days to the measurement site. The urban type derives from samples of pollution aerosol near urban centers, but is also present in other locations far from urban centers in the HSRL-1 database. The observation of small, spherical particles far from urban centers is consistent with other pollution sources, including power plants which are frequently far from cities.

The final type, fresh smoke, was based on known cases of fresh, visually distinct smoke plumes in the boundary layer close to the source, and classification results of this type usually indicate similar cases. These aerosols are also comprised of small spherical particles as indicated by the depolarization and backscatter color ratio measurements, and are primarily distinguished from other types by having lower lidar ratios (24-52 sr) than the pollution or smoke categories. This reflects similar findings by Alados-Arboledas et al. (2011) and Amiridis et al. (2009) who show that lidar ratio can be affected by the age of smoke. However, the optical properties of smoke can depend on other factors besides age, and the label "fresh smoke" is an approximate description. There are other cases in the HSRL-1 dataset identified as fresh smoke that are not obviously associated with fresh smoke plumes, still under investigation. An initial comparison with in situ measurements shows new particle formation, which can be associated with sulfate or organics (S. Crumeyrolle, personal communication, 2012) and which is, therefore, consistent with fresh smoke, but does not rule out pollution-related aerosol. There is no equivalent type in the CALIOP aerosol classification scheme, which includes only a single biomass burning type.

\subsection{CALIOP aerosol models}

CALIOP distinguishes among six types for the purpose of assigning the lidar ratios. These types are desert dust, polluted continental, biomass burning, polluted dust, maritime and clean continental. The types are described by Omar et al. (2009) with updates for V3.01 given in the
Data Quality Summary (http://www-calipso.larc.nasa.gov/ resources/calipso_users_guide/data_summaries/layer/\#dq); brief descriptions will be repeated here.

The desert dust model used in versions 1 and 2 of the CALIOP data products was derived using the discrete dipole approximation method (Omar et al., 2009). In the version 3 data products, the dust model was revised based on field measurements during the NAMMA field campaign combined with T-matrix calculations of particle phase functions (Omar et al., 2010). The modeled lidar ratios are comparable to measurements of African and Asian dust as well as transported dust having high values of depolarization that indicate that the dust is relatively pure. In the CALIOP typing algorithm, the model is applied to all aerosol layers exceeding a threshold depolarization measurement consistent with pure dust.

The polluted continental and biomass burning aerosol models were derived from cluster analysis of a multiyear AERONET dataset (Omar et al., 2005). The polluted continental model is applied to surface attached layers over land or ocean and to layers over tundra where the aerosol loading, indicated by the integrated attenuated backscatter, is significant, but where there is not enough depolarization to indicate significant influence from dust. The biomass burning model is applied to non-depolarizing elevated layers over ocean or those over land that have too much integrated attenuated backscatter to be background aerosol (i.e., clean continental).

The polluted dust model, which is applied to layers with intermediate depolarization, is a mixture of the CALIOP dust model and the AERONET cluster analysis results for biomass burning. In V3.01, the coarse mode is updated as described above for the desert dust model. The polluted dust model is intended to account for episodes of dust mixed with biomass burning and dust mixed with urban pollution.

The CALIOP marine aerosol model is derived from size distributions measured during the Shoreline Environmental Aerosol Study (SEAS) (Masonis et al., 2003). In the CALIOP algorithm, this model is applied to all surfaceattached aerosols over the ocean that are deemed not to be influenced by continental pollution.

The clean continental model is intended as a background aerosol type, for cases having very low aerosol loading. It was derived by fitting to measurements of long range continental transport. There is no corresponding "background" type in the HSRL-1 aerosol classification.

\section{Validation of CALIOP aerosol classification results}

\subsection{Overall comparison for 109 flights}

Validation underflights by HSRL-1 of the CALIPSO track present the opportunity to compare the HSRL-1 aerosol classification with the CALIOP Vertical Feature Mask (Winker et al., 2009; Powell et al., 2011). Figure 2 illustrates the 
Table 1. Ranges of the measured aerosol intensive parameters are given for all HSRL-1 classified measurements from 2006-2012. Ranges are given as first and last quartile, with 5th and 95th percentiles in parenthesis.

\begin{tabular}{lrrrr}
\hline Aerosol Type & $\begin{array}{r}\text { Aerosol } \\
\text { Depolarization (\%) }\end{array}$ & Lidar Ratio (sr) & $\begin{array}{r}\text { Backscatter color ratio } \\
(532 \mathrm{~nm}: 1064 \mathrm{~nm})\end{array}$ & $\begin{array}{r}\text { Depolarization } \\
\text { Spectral Ratio } \\
(1064 \mathrm{~nm}: 532 \mathrm{~nm})\end{array}$ \\
\hline Ice & $23-32(17-42)$ & $18-33(8-45)$ & $1.3-2.3(0.7-3.0)$ & $0.7-1.1(0.4-1.3)$ \\
Pure Dust & $31-33(30-35)$ & $45-51(41-57)$ & $1.4-1.6(1.0-1.7)$ & $0.9-1.0(0.8-1.1)$ \\
Dusty Mix & $13-20(10-28)$ & $29-49(14-63)$ & $1.3-1.8(1.1-2.3)$ & $1.1-1.7(0.8-2.1)$ \\
Marine & $4-9(2-13)$ & $17-27(9-33)$ & $1.3-1.6(1.2-1.8)$ & $0.5-1.1(0.2-1.5)$ \\
Polluted Marine & $3-5(1-6)$ & $36-45(27-50)$ & $1.5-1.7(1.3-1.8)$ & $1.1-2.0(0.4-2.8)$ \\
Urban & $3-7(2-10)$ & $53-70(43-81)$ & $1.7-2.1(1.4-2.5)$ & $1.5-2.3(1.1-3.1)$ \\
Smoke & $4-9(2-16)$ & $55-73(46-87)$ & $1.9-2.5(1.4-3.0)$ & $0.4-0.9(0.2-1.2)$ \\
Fresh Smoke & $3-6(2-8)$ & $33-46(24-52)$ & $2.1-2.5(1.9-2.8)$ & $0.9-1.7(0.3-2.3)$ \\
\hline
\end{tabular}

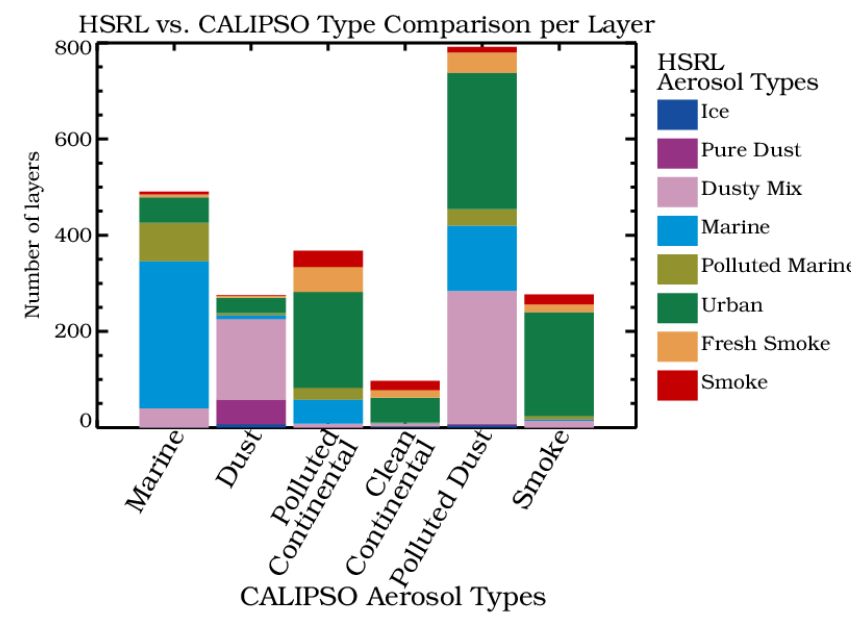

Fig. 2. Histogram showing the results of matching up HSRL-1 and CALIOP layer-by-layer for coincident flights, using CALIOP layer detection. The $\mathrm{x}$-axis shows the six CALIOP types and the colors indicate the HSRL types.

aerosol types determined using HSRL-1 measurements for aerosol layers detected by CALIOP. Recall that CALIOP aerosol typing is performed on integrated layers, which were detected in an earlier processing step on the basis of signal strength. In contrast, HSRL-1 typing is done for each rangeresolved measurement after minimal smoothing. So for this comparison, the CALIOP-detected layers are used and the HSRL-1 aerosol type for a given layer is taken to be the type of the majority of HSRL-1 classified points in the layer. All aerosol layers that are detected and classified by both instruments in 109 flights of HSRL-1 under the CALIPSO track are represented. For the most part there is reasonable agreement, given the different methodologies for assigning aerosol type and the differences in the overall sets of types discussed in Sect. 3.

The majority, $62 \%$, of the layers that are assigned marine by CALIOP are attributed by HSRL-1 to be mostly marine as well. An additional $16 \%$ of the CALIOP marine layers are classified by HSRL-1 as polluted marine, a closely related aerosol category. Since CALIOP has no polluted marine category, the choice of the marine type in these cases is probably the best choice. However, note that the HSRL-1 polluted marine type has a higher range of lidar ratios (36$45 \mathrm{sr}$ ) than the CALIOP marine type $(20 \mathrm{sr})$, so using the lidar ratio modeled for marine aerosol would lead to underestimating the AOT in these cases. This is in accord with the findings of other researchers who have observed that some CALIOP marine layers are probably composed of a mixture of marine aerosol with pollution or smoke from continental outflow (Oo and Holz, 2011; Schuster et al., 2012). Note that many of the HSRL-1 underflights of CALIPSO over water took place near the coasts, so the occurrence of polluted marine in this comparison, while instructive, is probably not representative of the true distribution of polluted marine cases in the CALIOP record.

Eighty percent of the layers that CALIOP classifies as dust have a majority classification by HSRL-1 of either pure dust or dusty mix. For both lidar systems, the depolarization measurement gives very reliable information about the presence of dust (Liu et al., 2012), since the depolarization measurement is sensitive to non-spherical particles. The distinction between pure dust and dusty mix (for HSRL-1) and between desert dust and polluted dust (for CALIOP) in both cases rests on setting a threshold value to indicate the minimum particulate depolarization of pure dust. The nominal CALIOP threshold is $20 \%$ (but see Sect. 4.5 for a more detailed explanation of how this is applied). In the HSRL-1 classification, the threshold is applied to a calculated fourdimensional distance that also takes the other three intensive variables into account (see Burton et al., 2012), but effectively the limit on the particle depolarization for pure dust is much higher, approximately $30 \%$. Therefore, the finding that many of the layers that CALIOP classifies as pure dust are characterized as a dust mixture by HSRL-1 is not surprising. 
Of the polluted continental layers, $54 \%$ are dominated by the HSRL-1 urban type, which is the closest match in terms of interpretation as well as lidar ratio.

Layers identified as polluted dust by CALIOP correlate with several different aerosol types inferred by HSRL-1 with no distinct majority. Of these layers, $35 \%$ are dominated by the HSRL- 1 type dusty mix, $36 \%$ by urban, and $17 \%$ by marine. Assignment to the polluted dust category assumes that these aerosols are made up of a mixture of dust and pollution or dust and smoke, so the presence of significant amounts of marine aerosol may indicate a dust mixture that is not well characterized, or may indicate that the polluted dust category is being misused in cases dominated by non-dust types. The presence of significant amounts of HSRL-1's urban type in the category polluted dust is at least a near match, since CALIOP's polluted dust model assumes a mixture between dust and pollution or smoke. However, this may reflect a misidentification of some layers that would be more appropriately handled as polluted continental, consistent with the inference of more fine mode in the CALIOP polluted dust cases than expected, as described by Oo and Holz (2011). Results for the polluted dust category will be discussed in more detail in several of the case studies in the next several subsections.

Finally, $78 \%$ of the aerosol layers that CALIOP labels as smoke are inferred by HSRL-1 to be urban aerosol, with only $13 \%$ categorized by HSRL-1 as smoke or fresh smoke. The two CALIOP types, smoke and polluted continental, are modeled with the same $532 \mathrm{~nm}$ lidar ratio so mistyping in these two categories is not of great concern in terms of a potential bias in the extinction and AOT retrievals. While mistyping between smoke and pollution aerosol is potentially more of a concern for other applications (e.g., validation of transport models, air quality monitoring and maintenance), these types are relatively difficult to separate using HSRL-1 measurements as well, partly because of the similarity in lidar ratio. While we believe that the spectral ratio of depolarization ratio is useful for separating smoke and urban aerosol in HSRL-1 measurements, better separation of these two types should be possible with the new, more advanced airborne HSRL-2 having HSRL capabilities at both 355 and $532 \mathrm{~nm}$. For these reasons we will not focus on this aspect of the comparison, which is best left for another study, and instead will focus primarily on cases featuring polluted dust.

\subsection{Example: well-separated layers}

Figure 3 shows the CALIOP and HSRL-1 aerosol type masks for a nighttime scene off the coast of the Eastern United States (Virginia and North Carolina) on 25 June 2006. HSRL-1 flew along the CALIPSO orbit track, observing the illustrated scene over a 53 min flight segment compared to an elapsed time of $52 \mathrm{~s}$ for CALIPSO. A tenuous elevated smoke layer (optical depth $\sim 0.026$ ) is present above $4 \mathrm{~km}$, advected from Canadian fires (see the US Air Quality Smog Blog
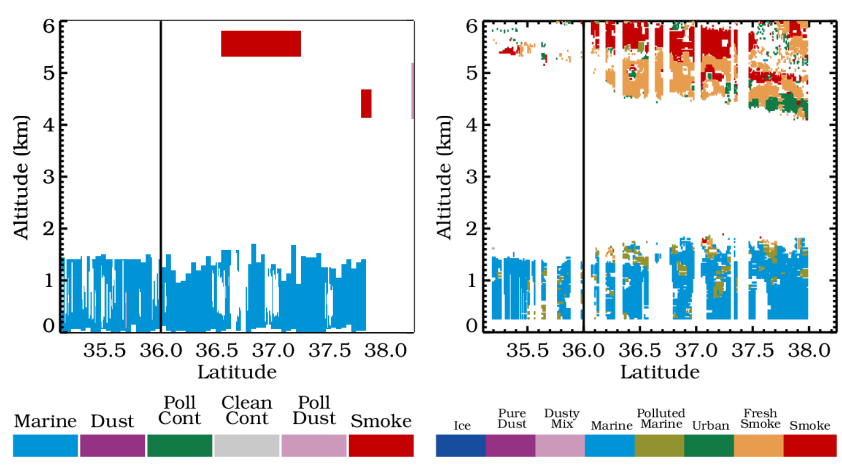

Fig. 3. Aerosol classification masks from CALIOP (left) and HSRL-1 (right) for a nighttime scene off the coast of Virginia and North Carolina on 25 June 2006, showing a tenuous elevated smoke layer and the marine boundary layer. Transit time for HSRL-1 on the B200 was 53 min compared to $52 \mathrm{~s}$ for CALIPSO.

archives at http://alg.umbc.edu/usaq/archives/2006_06.html). CALIOP and HSRL-1 agree well on the identification of the type of both the elevated layer and the marine boundary layer. The HSRL-1 classification identifies the elevated layer as a mixture of smoke and fresh smoke. The label fresh smoke here indicates parts of the layer having comparably lower lidar ratio, but in this case this probably does not relate to aging since the entire layer is several days removed from the source. Identification of the aerosol types is relatively straightforward for the CALIOP algorithm, since these are distinct layers conforming to the typical relations between type and location codified in the CALIOP typing algorithm, that is, the marine layer in contact with the ocean surface and a distinct elevated smoke layer. The next examples illustrate more complicated aerosol scenes.

\subsection{Example: dust mixture}

Figure 4 shows the CALIOP and HSRL-1 aerosol type masks for a nighttime scene in the Caribbean Sea on $26 \mathrm{Au}-$ gust 2010. Saharan dust is present above the marine boundary layer and to some extent mixing into the boundary layer, having advected across the Atlantic Ocean. Backtrajectory analysis (not shown) using the online Hybrid Single Particle Lagrangian Integrated Trajectory Model (HYSPLIT) tool from NOAA Air Resources (http://ready.arl.noaa.gov/ HYSPLIT.php) (Draxler and Rolph, 2013) is consistent with the transport of Saharan dust to this location. The shapes and locations of the detected aerosol layers agree very well in the CALIOP and HSRL-1 observations, and the inferred aerosol types also agree, in that both systems indicate marine aerosol in the lower layer and a dust mixture with some pure dust in the upper layer. For both the CALIOP and HSRL-1 measurements, the identification of a dust mixture is based primarily on measurements of non-zero depolarization in the scene that is nevertheless not strong enough to indicate pure dust. The dust in such a mixture dominates the lidar measurements that 

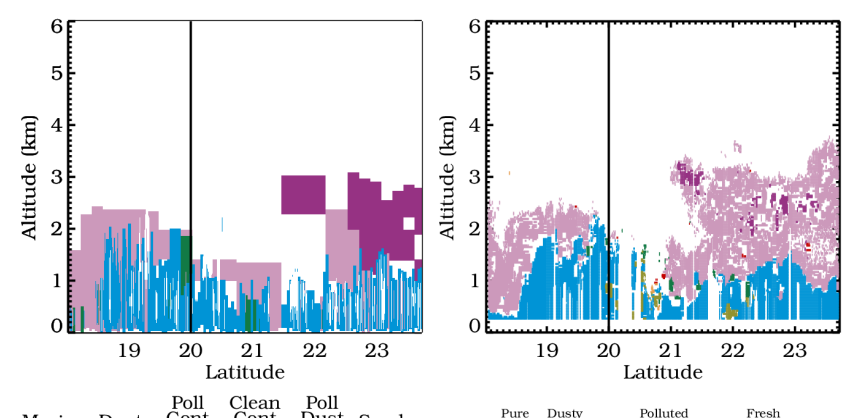

Marine Dust Cont Cont Dust Smoke

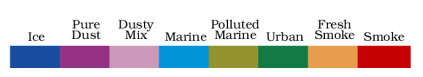

Fig. 4. Aerosol classification masks from CALIOP (left) and HSRL-1 (right) for a nighttime scene in the Caribbean Sea on 26 August 2010. Saharan dust which was advected across the Atlantic Ocean lies above the marine boundary layer. Transit time for HSRL-1 on the B200 was 94 min compared to $1.6 \mathrm{~min}$ for CALIPSO. The point of closest approach is indicated by a vertical line.

are used in the aerosol classification and it can be difficult to specify the aerosol type of the non-dust component. In this version of the HSRL-1 aerosol classification, there is a single dusty mix type and no attempt is made to specify the non-dust component. It is no easier for CALIOP to distinguish the non-dust component of such a mix; however, the CALIOP algorithm demands an assumption about the nondust component in order to model the lidar ratio. Therefore, CALIOP's dust mixture model, polluted dust, is designed as a mixture of dust and smoke or dust and pollution and has a relatively large lidar ratio of $55 \mathrm{sr}$ for version 3.01. The median HSRL-1-measured lidar ratio for this scene is much lower, $35 \mathrm{sr}$, indicating that a combination of dust plus marine aerosol would be a better choice for this scene.

\subsection{Example: layer boundaries and layers with multiple types}

Figure 5 illustrates another scene showing advected Saharan dust in the Caribbean, two days earlier on 24 August 2010. Again, CALIOP and HSRL-1 agree well on the overall shape of the detected aerosol layer and on its broad composition comprising marine aerosol, pure dust and a dust mixture. In contrast to the previous scene, however, the CALIOP aerosol classification mask for this scene does not show a clear distinction at the top of the boundary layer between the marine aerosol below and the dusty aerosol above. While a primary advantage of CALIPSO observations compared to passive satellites is its ability to make vertically resolved measurements of aerosol layer heights and vertical profiles of aerosol optical properties, detection of boundaries between aerosol layers of different types that are in contact with no clear air between them is a challenge. In the CALIOP algorithm, layer boundaries for contiguous aerosol layers are defined solely by changes in aerosol backscatter intensity as layers
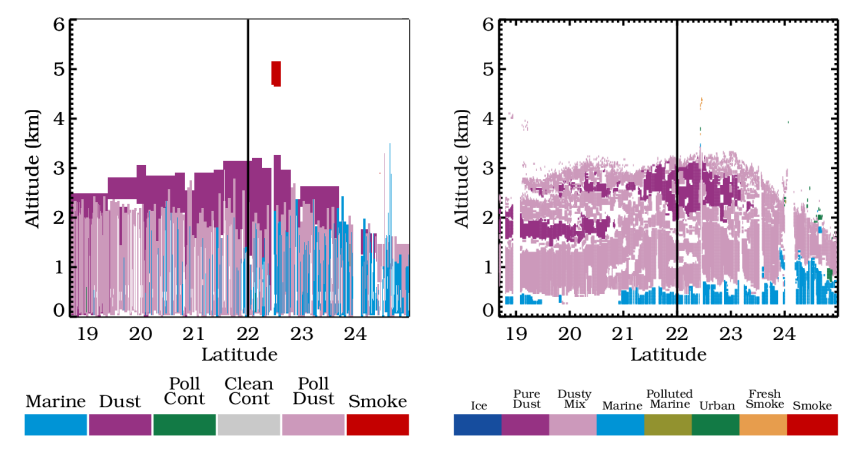

Fig. 5. Aerosol classification masks from CALIOP (left) and HSRL-1 (right) for a nighttime scene in the Caribbean Sea on 24 August 2010 (same as Fig. 1). Saharan dust which was advected across the Atlantic Ocean lies above the marine boundary layer. The CALIPSO satellite transited this scene in $1.7 \mathrm{~min}$. The transit time for the B200 with HSRL aboard was $101 \mathrm{~min}$. The point of closest approach is indicated by a vertical line.

are detected at successively coarser averaging resolutions in the multi-resolution layer detection algorithm (Vaughan et al., 2009). While aerosols of different origin may indeed differ in backscatter intensity, this is a less reliable guide to aerosol layer boundaries than intensive parameters like measured lidar ratio (from HSRL-1) or depolarization (in the case of layers containing some dust). Therefore, it is possible for a single layer identified by CALIOP to be composed of regions of different aerosol types. This presents an additional source of error in the inferred lidar ratio for these layers, which might be more accurately modeled as an external mixture of multiple types.

To better understand how often these multi-type layers occur, we re-examined the HSRL-1 aerosol classification results within layers. In the 109 coincident flights, a single HSRL- 1 aerosol type accounts for $90 \%$ of the AOT (as measured by HSRL-1) in only $26 \%$ of the CALIPSO layers (the $90 \%$ AOT threshold is used since there is some noise in the HSRL classification). Two aerosol types are required to account for $90 \%$ of the AOT in $35 \%$ of layers, 3 aerosol types in $27 \%$ of layers, and more than 3 aerosol types in $12 \%$ of the layers in this comparison. The fraction of layers comprising more than one type is fairly consistent across CALIOP types, ranging from $57 \%$ to $86 \%$ for the six CALIOP types. Table 2 breaks down these cases according to which two HSRL-1 types contribute the most. Twenty-four percent of CALIOP marine layers in this comparison contain aerosol that HSRL- 1 characterizes as a dusty mix (13\%) or a combination of marine and dusty mix (11\%). Likewise, $11 \%$ of the CALIOP desert dust layers and $14 \%$ of the CALIOP polluted dust layers are characterized by HSRL-1 as a combination of dusty mix and marine aerosol. The 24 August 2010 case study shown in Fig. 5, where the boundary between the marine layer and the overlying dust layer is not well characterized, is reflected in these numbers. 
Table 2. The most frequent combinations of HSRL-1 types within CALIOP layers of a given type are listed. When more than one HSRL-1 type contribute to make up $90 \%$ of the AOT within a layer, the top two contributing HSRL-1 types are given.

\begin{tabular}{|c|c|c|}
\hline CALIOP Layer type & HSRL-1 types & Percentage of layers \\
\hline \multirow[t]{6}{*}{ Marine } & Marine and Polluted Marine & $22 \%$ \\
\hline & Marine only & $13 \%$ \\
\hline & Dusty Mix only & $13 \%$ \\
\hline & Marine and Dusty Mix & $11 \%$ \\
\hline & Marine and Urban & $10 \%$ \\
\hline & Other combinations & $31 \%(<10 \%$ each $)$ \\
\hline \multirow[t]{5}{*}{ Dust } & Dusty Mix and Pure Dust & $28 \%$ \\
\hline & Dusty Mix and Urban & $14 \%$ \\
\hline & Dusty Mix and Marine & $11 \%$ \\
\hline & Dusty Mix only & $10 \%$ \\
\hline & Other combinations & $37 \%(<10 \%$ each $)$ \\
\hline \multirow[t]{4}{*}{ Polluted Continental } & Urban and Fresh Smoke & $19 \%$ \\
\hline & Urban and Smoke & $14 \%$ \\
\hline & Urban only & $12 \%$ \\
\hline & Other combinations & $55 \%(<10 \%$ each $)$ \\
\hline \multirow[t]{4}{*}{ Clean Continental } & Urban and Smoke & $20 \%$ \\
\hline & Smoke and Fresh Smoke & $17 \%$ \\
\hline & Urban and Fresh Smoke & $10 \%$ \\
\hline & Other combinations & $53 \%(<10 \%$ each $)$ \\
\hline \multirow[t]{4}{*}{ Polluted Dust } & Dusty Mix and Urban & $16 \%$ \\
\hline & Dusty Mix and Marine & $14 \%$ \\
\hline & Dusty Mix and Pure Dust & $10 \%$ \\
\hline & Other combinations & $60 \%(<10 \%$ each $)$ \\
\hline \multirow[t]{5}{*}{ Smoke } & Urban only & $32 \%$ \\
\hline & Smoke and Urban & $17 \%$ \\
\hline & Fresh Smoke and Urban & $13 \%$ \\
\hline & Urban and Dusty Mix & $11 \%$ \\
\hline & Other combinations & $27 \%(<10 \%$ each $)$ \\
\hline
\end{tabular}

According to Table 2, a significant fraction of other CALIOP layers that are modeled as pure marine are comprised of combinations of aerosols that HSRL-1 describes as marine plus polluted marine $(22 \%)$ or marine plus urban $(10 \%)$. This finding supports the discussion of Oo and Holz (2011) and Schuster et al. (2012) who indicate that CALIOP marine layers can be contaminated by pollution.

\subsection{Example: overuse of polluted dust and desert dust}

The final example illustrates a contrasting case, in which the CALIOP aerosol type mask indicates a wider variety of types than the HSRL-1 classification. Figure 6 shows a scene near Washington DC on 4 August 2007. On this day, during the CALIPSO and Twilight Zone (CATZ) field campaign, heavy haze was observed with high aerosol optical depths of 0.7 to 1.0 over the southern half of the scene. The HSRL-1 aerosol classification indicates mainly pollution aerosol with some smoke (in optically thinner parts of the layer), in agreement with a discussion of the same case study
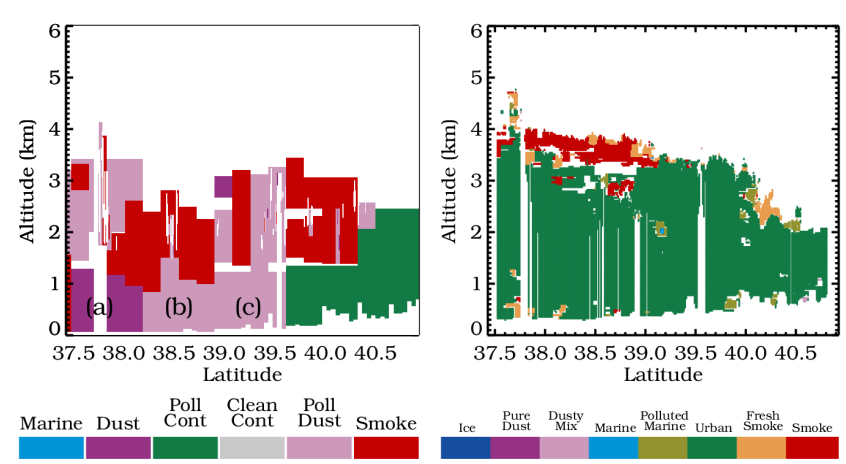

Fig. 6. Aerosol classification masks for CALIOP (left) and HSRL-1 (right) for a daytime scene near Washington DC on 4 August 2007. Transit time for the HSRL aboard the B200 was $50 \mathrm{~min}$ for this scene. CALIPSO transited the same scene in $1.0 \mathrm{~min}$. In this case, the flight segment ended approximately $13 \mathrm{~min}$ before the CALIPSO overpass time. 
by Kacenelenbogen et al. (2011). In contrast, the CALIOP aerosol type mask is less homogeneous and includes significant regions of polluted dust and pure dust in addition to pollution and smoke. The distinct boundaries between aerosol types in the CALIOP aerosol type mask are reflected in discontinuities in the lidar ratio and retrieved products. A similar effect was noted by Campbell et al. (2012) as a discontinuity in aerosol optical depth at the coastline, a statistical effect caused by the fact that certain aerosol types are limited to either land or water. However, as illustrated by Fig. 6 , discontinuities between types are also present at the scale of a single CALIOP data scene.

The smoke and polluted continental aerosol types present in this scene are consistent with the types observed by HSRL-1. However, the polluted dust and desert dust are less appropriate. The HSRL-1 measured aerosol depolarization does not exceed $15 \%$ for this scene and is, therefore, inconsistent with HSRL-1 observations of dust and dust mixtures; however, the CALIOP aerosol type mask indicates both polluted dust and pure dust in this scene. Part of this is explained by lower depolarization thresholds for pure dust and polluted dust in the CALIOP typing scheme, $20 \%$ and $7.5 \%$, respectively (Omar et al., 2009). The higher effective aerosol depolarization threshold for dust mixtures in HSRL is related to measurement samples where the type is known, including smoke observations from a plume identified visually from the cockpit with aerosol depolarization of approximately $10 \%$; this suggests that the lower CALIOP threshold may be too low. Yet, some of the desert dust and polluted dust layers in this scene have smaller reported aerosol depolarization values than even these lower thresholds. Specifically, in the lower layers, those with layer tops below about $1300 \mathrm{~m}$, the reported layer-averaged particle depolarization in the CALIOP product files are below the thresholds for the assigned type. According to the CALIOP aerosol layer product, the dust layer labeled (a) in Fig. 6 has a measured aerosol depolarization ratio of $14 \%$, while the two polluted dust layers (b) and (c) have aerosol depolarization ratios of $4.7 \%$ and $6 \%$, respectively.

To understand this discrepancy, it is important to realize that while CALIOP's measurement of volume depolarization is highly reliable (Liu et al., 2012), the depolarization value used in the aerosol type identification is an estimate, an intermediate product which is affected by attenuation, sometimes dramatically. Omar et al. (2009) detail how the volume depolarization is corrected for molecular depolarization to produce an estimated aerosol depolarization as part of the aerosol classification algorithm using the following equation.

$\delta_{\mathrm{p}}^{\text {est }}=\frac{\delta_{\mathrm{v}}\left[(R-1)\left(1+\delta_{\mathrm{m}}\right)+1\right]-\delta_{\mathrm{m}}}{(R-1)\left(1+\delta_{\mathrm{m}}\right)+\delta_{\mathrm{m}}-\delta_{\mathrm{v}}}$

where $\delta_{\mathrm{v}}$ indicates the volume depolarization, $\delta_{\mathrm{m}}$ indicates the molecular depolarization, $\delta_{\mathrm{p}}^{\text {est }}$ indicates the estimated aerosol depolarization, and $R$ indicates the total scattering ratio (TSR), which is the ratio of the total backscattering
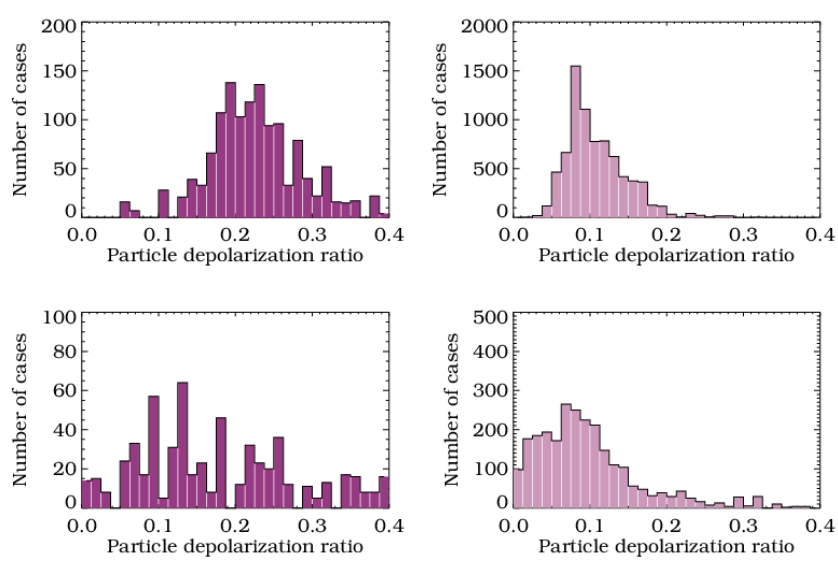

Fig. 7. Histograms illustrate all pure dust layers (left two panels) and polluted dust layers (right two panels) identified in CALIOP v3.01 data for August 2006, over the continental US, as a function of the particle depolarization from the final product and overlying attenuated backscatter. The top panels show layers where the overlying attenuated backscatter is less than $0.015 \mathrm{sr}^{-1}$ and the bottom panels show layers where the overlying attenuated backscatter is greater than $0.015 \mathrm{sr}^{-1}$. Note the distributions shift to the left indicating that attenuation affects the classification results.

(aerosol plus molecular) to the molecular backscattering. The total scattering ratio used in this calculation has not yet been corrected for attenuation of the laser light between the satellite and the layer being investigated. The molecular depolarization correction given by the equation almost always increases depolarization over the volume depolarization value, and the contribution of the molecular correction is larger at smaller TSR values. Since attenuation causes the TSR to be underestimated, the aerosol depolarization is overestimated and a classification of pure dust or polluted dust becomes more likely.

Figure 7 illustrates the bias towards classification of desert dust or polluted dust as attenuation increases. The figure shows histograms of all V3.01 CALIOP-detected layers in the desert dust and polluted dust categories for the month of August 2006 over the continental United States. The histograms are shown as a function of particle depolarization, segregated into two categories with differing amounts of overlying attenuated backscatter. Here, the particle depolarization, obtained from the CALIOP product files, was calculated from attenuation-corrected signals and so is a more accurate measurement than the estimate of particle depolarization that was used in the aerosol classification stage. When there is little attenuation (top panels), the distribution of aerosol depolarization ratio for polluted dust is centered near $8 \%$ and for desert dust is centered near $19-23 \%$. However, when there is significant attenuation (bottom panels), the distributions shift towards smaller aerosol depolarization. In the presence of a large amount of attenuation, classification of some layers as polluted dust and desert dust occurs when the 
aerosol depolarization is extremely small, just a fraction of a percent, due to its being overestimated in the aerosol classification stage.

The estimated particle depolarization could be improved by correcting the TSR for attenuation. While it is not possible to correct for attenuation caused by upper parts of the layer under consideration (since this calculation is done before the extinction retrieval for a given aerosol layer), much of the attenuation affecting TSR is from layers above the current layer. Since the extinction retrieval for upper layers is already complete, attenuation by overlying layers should be corrected and will be corrected in Version 4 of the Level 2 retrieval algorithms. Recall that the scene illustrated in Fig. 6 has quite significant aerosol loading $(\mathrm{AOT}=0.8-1.0)$ and it is only the lower layers that are "misclassified" according to the CALIOP depolarization thresholds; therefore, correcting for attenuation by overlying layers is expected to fix much of the bias. It is important to note that this attenuation bias is only relevant to the aerosol classification, since attenuation is taken into account in the final aerosol depolarization product.

\section{Hybrid HSRL + CALIPSO experiment}

Since the HSRL-1 instrument is analogous to CALIOP but with additional channels, the coincident measurements by the airborne HSRL-1 present a unique opportunity to investigate a more direct comparison between the aerosol classification algorithms themselves, operating on identical data. Using a similar strategy to Burton et al. (2010), we use only the parallel and perpendicular total backscattering signals which HSRL-1 has in common with CALIOP and do not use the molecular channel or the $1064 \mathrm{~nm}$ depolarization ratio. For this comparison, measurements of attenuated backscatter from HSRL-1 are used as input to the CALIOP retrieval algorithms, thus producing similar data products to CALIOP, including the aerosol type product. We will refer to this combination of data measured by HSRL-1 and retrieved using CALIOP algorithms as the "hybrid HSRL-CALIOP" retrieval.

The agreement from the hybrid HSRL-CALIOP retrieval compared to the HSRL-1 aerosol classification increases for some types and decreases for others, with respect to the previous comparison between CALIOP v3.01 and HSRL-1. Specifically, the best agreement is now in the polluted continental category. A large majority, $71 \%$, of the layers identified as polluted continental by the hybrid system are dominated by the HSRL-1 urban type, which is greater agreement than the $54 \%$ seen in the comparison of CALIOP and HSRL-1 classifications. Agreement in the smoke category also improves dramatically; $51 \%$ of the layers that the hybrid identifies as smoke are predominately smoke or fresh smoke in the HSRL-1 classification (up from only 13\%). On the other hand, agreement for the dust and marine categories decreases. Only $68 \%$ of the hybrid desert dust layers
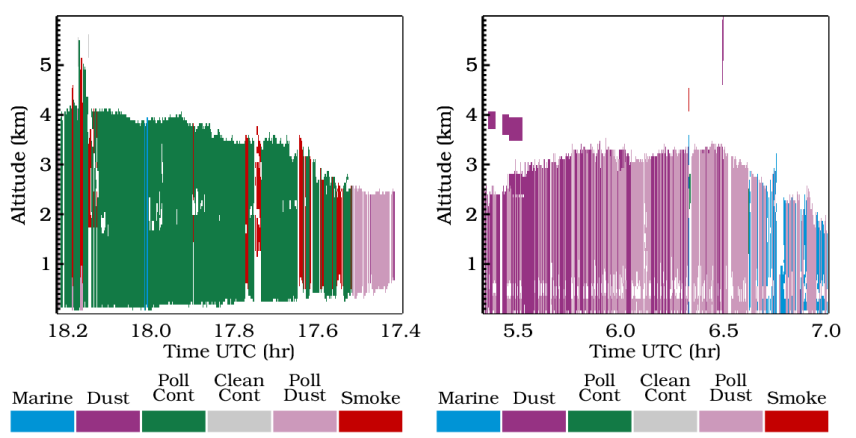

Fig. 8. Aerosol classification mask for data obtained by the airborne HSRL-1, but processed using the CALIOP retrieval software. Left panel shows the aerosol classification for 4 August 2007 near Washington DC (as in Fig. 6) and the right panel is 24 August 2010 in the Caribbean Sea (as in Fig. 5).

are considered dust or dusty mix in the HSRL-1 classification results (compared to $80 \%$ for the comparison of the CALIOP and HSRL-1 classification results) and only $42 \%$ (compared to $62 \%$ ) of the layers identified by the hybrid as marine are dominated by marine in the HSRL-1 classification. For polluted dust layers, the comparison is still poor, with only $33 \%$ of polluted dust layers in the hybrid retrievals characterized as dusty mix in the HSRL-1 classification scheme.

Although there is increased agreement in some categories, it is perhaps surprising that using the HSRL-1 data as input to both algorithms does not result in more uniform improvement in all categories. Recall that this experiment is a direct comparison of the two aerosol classification algorithms, both operating on the same underlying data, and so might be expected to produce excellent agreement in all categories. In fact, the airborne HSRL-1 measurements have a higher signal-to-noise ratio than the CALIOP measurements, and might be expected to improve the classification for that reason. Further investigation reveals that the relative lack of agreement is related to an almost complete nondetection of internal layer boundaries. In the CALIOP algorithm, layer boundaries are defined solely by changes in aerosol backscatter intensity, as discussed in Sect. 4.4, not changes in aerosol type. Re-examination of two of the above examples will serve to explain how this affects the type comparison.

Figure 8 shows the aerosol classification mask from the hybrid measurements comprised of Level-1-like data measured by HSRL-1 and retrieved via the CALIOP algorithms, for the 4 August 2007 and 24 August 2010 cases (the same scenes shown in Figs. 6 and 5, respectively). The classification in the 2007 Washington DC case is improved compared to Fig. 6, for now most of the scene is identified as polluted continental, in good agreement with the identification of urban aerosol from the HSRL-1 classification. In contrast, the classification for the 2010 Caribbean case is less accurate than the CALIOP classification shown in Fig. 5, as now 
almost none of the aerosol is identified as marine. An obvious feature of the aerosol classification masks from the hybrid retrieval in both cases is the fact that most of the identified aerosol layers extend all the way from the highest altitude where aerosol is detected down to the surface; in other words, there are almost no internal boundaries between types. The reason for this is that the higher signal-to-noise ratio from HSRL-1 allowed the CALIOP retrieval algorithm to detect most of the aerosol layers at the smallest averaging resolution, $5 \mathrm{~km}$. In fact, the CALIOP detection algorithm is quite robust and accurately detects very tenuous aerosol layers in the data. However, since all the aerosol in Fig. 8 is detected in a single pass through the CALIOP multi-averaging detection scheme, each column includes only a single layer, and that layer is assigned a single type by the algorithm. This effect explains both the better agreement between the hybrid HSRL-CALIOP system and HSRL-1 observations for the Washington DC case and the worse agreement in the Caribbean case. In both cases, since only a single layer is detected, the observed aerosol depolarization is averaged over the entire height of the aerosol column. Therefore, the layeraveraged aerosol depolarization in the pollution case drops below the detection threshold for the polluted dust category across most of the scene. In the Caribbean case, the aerosol depolarization averaged over the entire aerosol column is still large enough to trigger a classification of polluted dust or desert dust and too high to be considered maritime, so the maritime layers and the dust layers that were present in the same column in the CALIOP classification are effectively combined together in the hybrid retrieval into singlelayer columns of pure dust or polluted dust. It is important to note that the multi-resolution layer detection algorithm of CALIOP is well designed for the lower signal-to-noise observations of the satellite instrument, so the lack of internal layer boundaries in the hybrid experiment should not be taken to indicate a flaw in the CALIOP algorithms. However, this result illustrates how the CALIOP scheme can fail to identify different aerosol types within a single column, since internal boundaries between aerosol types in the CALIOP products are primarily related to changes in backscatter intensity rather than aerosol intensive parameters that are directly linked to aerosol type. The relatively poor agreement in some categories, in common with the original comparison, also reinforces that it is not primarily the increased signal-to-noise ratio that allows for more accurate aerosol classification from the HSRL-1 measurements, but the increased information content, in the form of aerosol intensive parameters that give direct insight into aerosol type.

\section{Summary and discussion}

In this study, we have compared the aerosol classification products from CALIOP with those from the NASA Langley airborne HSRL-1 instrument. The HSRL-1 aerosol classification makes use of four aerosol intensive properties that depend only on aerosol type and not amount to classify each range-resolved measurement. The CALIOP aerosol classification strategy is necessarily different, since aerosol type is a required input for the extinction retrieval. The CALIOP typing uses an estimate of aerosol depolarization, attenuated backscatter, layer height and location information. It is done on integrated layers that are detected by a separate algorithm that is not designed to detect differences in aerosol type. For this comparison, all aerosol layers on 109 underflights of the CALIOP orbit track were examined, showing best agreement for desert dust and marine layers, and relatively poor agreement for smoke and polluted dust layers. To gain a better understanding of these overall results, we examined individual case studies which yielded specific insights which could potentially lead to incremental improvements in the CALIOP aerosol classification product.

First, we find that the CALIOP polluted dust category includes not just the cases of dust mixed with pollution or smoke for which it was designed, but also cases where dust is mixed with marine aerosol. An improvement to the inferred lidar ratio for dust mixtures would be possible if the typing algorithm were refined to distinguish between different dust mixtures, specifically between mixtures of dust plus pollution or smoke, which would have a lidar ratio greater than pure dust, and mixtures of dust plus marine, which would have a lidar ratio less than pure dust. It may be possible to separate different dust mixtures in the CALIOP retrieval by adding the attenuated backscatter color ratio to the information that is used for diagnosing aerosol type. Although the color ratio from the attenuated backscatter (i.e., Level 1 data) is not the same as the true backscatter color ratio (which depends on selection of the lidar ratios), the work of Oo and Holz (2011) on cases over water (without dust) suggests that CALIOP's attenuated backscatter color ratio may be sufficient to distinguish marine aerosol from smoke aerosol. Research is ongoing as to whether there is sufficient particlesize information in the attenuated backscatter color ratio to distinguish mixtures of dust and marine from mixtures of dust and smoke or pollution.

Second, we find that the polluted dust and desert dust types are found more frequently in CALIOP data than in HSRL-1 data for two reasons. The first is smaller thresholds on depolarization for these types in the CALIOP algorithm compared to the HSRL-1 aerosol typing algorithm. The second and more important reason is an attenuation-related depolarization bias. A correction for attenuation should be included in the estimated aerosol depolarization that is used in the classification. In fact, the CALIOP team plans to correct for attenuation in overlying layers in the version 4.0 release of CALIOP Level 2 processing. Correcting for overlying layers will be relatively straightforward, since the current retrieval completely solves each layer before moving to lower layers.

Our final finding is that the reported layer heights of contiguous aerosol layers of different types do not accurately 
reflect the boundaries between different aerosol types. The detection algorithm is not designed to separate aerosol by type and can fail to identify different aerosol types within a column. Rather, internal boundaries between aerosol types in the CALIOP layers are related only to detection resolution. In specific cases like the Caribbean example studied here, where two aerosol types with differing amounts of depolarization occur in contiguous layers, CALIOP theoretically has the information content to separate them. It may be profitable to use the CALIOP depolarization measurements to refine the detected layer boundaries in such cases.

As stated above, the primary role of the aerosol classification in the CALIOP algorithms is to enable an accurate inference of the lidar ratio for use in the retrieval of aerosol extinction and backscatter profiles. However, the combination of qualitative knowledge of the aerosol type with accurate quantitative profile measurements has other useful applications, including model assessment and improvement, and air quality detection and management. Based on our results, a future satellite lidar similar to CALIOP, but with the addition of polarization sensitivity at $1064 \mathrm{~nm}$ and the HSRL technique at $532 \mathrm{~nm}$ could provide a significant advancement in characterizing the vertical distribution of aerosol for climate and air quality applications.

Recently, LaRC has built and deployed a follow-on instrument, HSRL-2, the first airborne multi-wavelength HSRL instrument, with HSRL capabilities at both 355 and $532 \mathrm{~nm}$ (http://fallmeeting.agu.org/2012/files/2012/12/ A13K-0336_Hostetler_et_al.pdf). It also uses the standard backscatter technique at $1064 \mathrm{~nm}$ and measures depolarization at all three channels. This combination of measurements provides additional information content and is expected to provide aerosol classification improvements over the HSRL-1 classification studied here.

Acknowledgements. Funding for this research came from the NASA Headquarters Science Mission Directorate Radiation Sciences Program; the NASA CALIPSO project; and the US Department of Energy's Atmospheric Science Program Atmospheric System Research, an Office of Science, Office of Biological and Environmental Research program, under Grant No. DE-AI02-05ER63985. The authors also acknowledge the NOAA Air Resources Laboratory (ARL) for the provision of the HYSPLIT transport and dispersion model and READY website (http://www.arl.noaa.gov/ready.php) used for some of the analysis described in this presentation. The authors would also like to thank the NASA Langley B200 King Air flight crew for their outstanding work in support of HSRL measurements, the engineering team who work untiringly on building and maintaining excellent HSRL instruments, and our colleagues who operated HSRL-1 in flight and processed the measurements.

Edited by: P. Di Girolamo

\section{References}

Alados-Arboledas, L., Müller, D., Guerrero-Rascado, J. L., NavasGuzmán, F., Pérez-Ramírez, D., and Olmo, F. J.: Optical and microphysical properties of fresh biomass burning aerosol retrieved by Raman lidar, and star-and sun-photometry, Geophys. Res. Lett., 38, L01807, doi:10.1029/2010g1045999, 2011.

Amiridis, V., Balis, D. S., Giannakaki, E., Stohl, A., Kazadzis, S., Koukouli, M. E., and Zanis, P.: Optical characteristics of biomass burning aerosols over Southeastern Europe determined from UVRaman lidar measurements, Atmos. Chem. Phys., 9, 2431-2440, doi:10.5194/acp-9-2431-2009, 2009.

Burton, S. P., Ferrare, R. A., Hostetler, C. A., Hair, J. W., Kittaka, C., Vaughan, M. A., Obland, M. D., Rogers, R. R., Cook, A. L., Harper, D. B., and Remer, L. A.: Using airborne high spectral resolution lidar data to evaluate combined active plus passive retrievals of aerosol extinction profiles, J. Geophys. Res.-Atmos., 115, D00H15, doi:10.1029/2009jd012130, 2010.

Burton, S. P., Ferrare, R. A., Hostetler, C. A., Hair, J. W., Rogers, R. R., Obland, M. D., Butler, C. F., Cook, A. L., Harper, D. B., and Froyd, K. D.: Aerosol classification using airborne High Spectral Resolution Lidar measurements methodology and examples, Atmos. Meas. Tech., 5, 73-98, doi:10.5194/amt-5-73-2012, 2012.

Campbell, J. R., Reid, J. S., Westphal, D. L., Zhang, J., Hyer, E. J., and Welton, E. J.: CALIOP aerosol subset processing for global aerosol transport model data assimilation, IEEE J. Sel. Top. Appl., 3, 203-214, doi:10.1109/jstars.2010.2044868, 2010.

Campbell, J. R., Reid, J. S., Westphal, D. L., Zhang, J., Tackett, J. L., Chew, B. N., Welton, E. J., Shimizu, A., Sugimoto, N., Aoki, K., and Winker, D. M.: Characterizing the vertical profile of aerosol particle extinction and linear depolarization over southeast Asia and the maritime continent: the 2007-2009 view from CALIOP, Atmos. Res., 122, 520-543, doi:10.1016/j.atmosres.2012.05.007, 2012.

de Foy, B., Burton, S. P., Ferrare, R. A., Hostetler, C. A., Hair, J. W., Wiedinmyer, C., and Molina, L. T.: Aerosol plume transport and transformation in high spectral resolution lidar measurements and WRF-Flexpart simulations during the MILAGRO Field Campaign, Atmos. Chem. Phys., 11, 3543-3563, doi:10.5194/acp-11-3543-2011, 2011.

Draxler, R. R. and Rolph, G. D.: HYSPLIT (HYbrid Single-Particle Lagrangian Integrated Trajectory) Model access via NOAA ARL READY Website (http://ready.arl.noaa.gov/HYSPLIT.php) (last access: 21 May 2013), NOAA Air Resources Laboratory, Silver Spring, MD, 2013.

Ford, B. and Heald, C. L.: An A-train and model perspective on the vertical distribution of aerosols and $\mathrm{CO}$ in the Northern Hemisphere, J. Geophys. Res., 117, D06211, doi:10.1029/2011jd016977, 2012.

Freudenthaler, V., Esselborn, M., Wiegner, M., Heese, B., Tesche, M., Ansmann, A., Muller, D., Althausen, D., Wirth, M., Fix, A., Ehret, G., Knippertz, P., Toledano, C., Gasteiger, J., Garhammer, M., and Seefeldner, M.: Depolarization ratio profiling at several wavelengths in pure Saharan dust during SAMUM 2006, Tellus B, 61, 165-179, doi:10.1111/j.16000889.2008.00396.x, 2009.

Gasteiger, J., Wiegner, M., Groß, S., Freudenthaler, V., Toledano, C., Tesche, M., and Kandler, K.: Modelling lidarrelevant optical properties of complex mineral dust aerosols, 
Tellus B, 63, 725-741, doi:10.1111/j.1600-0889.2011.00559.x, 2011.

Groß, S., Tesche, M., Freudenthaler, V., Toledano, C., Wiegner, M., Ansmann, A., Althausen, D., and Seefeldner, M.: Characterization of Saharan dust, marine aerosols and mixtures of biomassburning aerosols and dust by means of multi-wavelength depolarization and Raman lidar measurements during SAMUM 2, Tellus B, 63, 706-724, doi:10.1111/j.1600-0889.2011.00556.x, 2011.

Grund, C. J. and Eloranta, E. W.: University-of-Wisconsin high spectral resolution lidar, Opt. Eng., 30, 6-12, 1991.

Hair, J. W., Hostetler, C. A., Cook, A. L., Harper, D. B., Ferrare, R. A., Mack, T. L., Welch, W., Izquierdo, L. R., and Hovis, F. E.: Airborne high spectral resolution lidar for profiling aerosol optical properties, Appl. Optics, 47, 6734-6752, doi:10.1364/AO.47.006734, 2008.

Holben, B. N., Eck, T. F., Slutsker, I., Tanré, D., Buis, J. P., Setzer, A., Vermote, E., Reagan, J. A., Kaufman, Y. J., Nakajima, T., Lavenu, F., Jankowiak, I., and Smirnov, A.: AERONET - a federated instrument network and data archive for aerosol characterization, Remote Sens. Environ., 66, 1-16, 1998.

Hunt, W. H., Winker, D. M., Vaughan, M. A., Powell, K. A., Lucker, P. L., and Weimer, C.: CALIPSO lidar description and performance assessment, J. Atmos. Ocean. Tech., 26, 12141228, doi:10.1175/2009jtecha1223.1, 2009.

Kacenelenbogen, M., Vaughan, M. A., Redemann, J., Hoff, R. M., Rogers, R. R., Ferrare, R. A., Russell, P. B., Hostetler, C. A., Hair, J. W., and Holben, B. N.: An accuracy assessment of the CALIOP/CALIPSO version 2/version 3 daytime aerosol extinction product based on a detailed multi-sensor, multiplatform case study, Atmos. Chem. Phys., 11, 3981-4000, doi:10.5194/acp-11-3981-2011, 2011.

Koffi, B., Schulz, M., Bréon, F.-M., Griesfeller, J., Winker, D., Balkanski, Y., Bauer, S., Berntsen, T., Chin, M., Collins, W. D., Dentener, F., Diehl, T., Easter, R., Ghan, S., Ginoux, P., Gong, S., Horowitz, L. W., Iversen, T., Kirkevåg, A., Koch, D., Krol, M., Myhre, G., Stier, P., and Takemura, T.: Application of the CALIOP layer product to evaluate the vertical distribution of aerosols estimated by global models: AeroCom phase I results, J. Geophys. Res., 117, D10201, doi:10.1029/2011jd016858, 2012.

Liu, Z., Vaughan, M., Winker, D., Kittaka, C., Getzewich, B., Kuehn, R., Omar, A., Powell, K., Trepte, C., and Hostetler, C.: The CALIPSO lidar cloud and aerosol discrimination: version 2 algorithm and initial assessment of performance, J. Atmos. Ocean. Tech., 26, 1198-1213, doi:10.1175/2009jtecha1229.1, 2009.

Liu, Z., Fairlie, T. D., Uno, I., Huang, J., Wu, D., Omar, A., Kar, J., Vaughan, M., Rogers, R., Winker, D., Trepte, C., Hu, Y., Sun, W., Lin, B., and Cheng, A.: Transpacific transport and evolution of the optical properties of Asian dust, J. Quant. Spectrosc. Ra., 116, 24-33, doi:10.1016/j.jqsrt.2012.11.011, 2013.

Masonis, S. J., Anderson, T. L., Covert, D. S., Kapustin, V., Clarke, A. D., Howell, S., and Moore, K.: A study of the extinction-to-backscatter ratio of marine aerosol during the shoreline environment aerosol study, J. Atmos. Ocean. Tech., 20, 1388-1402, doi:10.1175/15200426(2003)020<1388:asoter >2.0.co;2, 2003.

McNaughton, C. S., Clarke, A. D., Kapustin, V., Shinozuka, Y., Howell, S. G., Anderson, B. E., Winstead, E., Dibb, J.,
Scheuer, E., Cohen, R. C., Wooldridge, P., Perring, A., Huey, L. G., Kim, S., Jimenez, J. L., Dunlea, E. J., DeCarlo, P. F., Wennberg, P. O., Crounse, J. D., Weinheimer, A. J., and Flocke, F.: Observations of heterogeneous reactions between Asian pollution and mineral dust over the Eastern North Pacific during INTEX-B, Atmos. Chem. Phys., 9, 8283-8308, doi:10.5194/acp-9-8283-2009, 2009.

Mielonen, T., Arola, A., Komppula, M., Kukkonen, J., Koskinen, J., de Leeuw, G., and Lehtinen, K. E. J.: Comparison of CALIOP level 2 aerosol subtypes to aerosol types derived from AERONET inversion data, Geophys. Res. Lett., 36, L18804, doi:10.1029/2009g1039609, 2009.

Molina, L. T., Madronich, S., Gaffney, J. S., Apel, E., de Foy, B., Fast, J., Ferrare, R., Herndon, S., Jimenez, J. L., Lamb, B., Osornio-Vargas, A. R., Russell, P., Schauer, J. J., Stevens, P. S., Volkamer, R., and Zavala, M.: An overview of the MILAGRO 2006 Campaign: Mexico City emissions and their transport and transformation, Atmos. Chem. Phys., 10, 8697-8760, doi:10.5194/acp-10-8697-2010, 2010.

Müller, D., Ansmann, A., Mattis, I., Tesche, M., Wandinger, U., Althausen, D., and Pisani, G.: Aerosol-type-dependent lidar ratios observed with Raman lidar, J. Geophys. Res.-Atmos., 112, D16202, doi:10.1029/2006jd008292, 2007.

Omar, A. H., Won, J.-G., Winker, D. M., Yoon, S.-C., Dubovik, O., and McCormick, M. P.: Development of global aerosol models using cluster analysis of Aerosol Robotic Network (AERONET) measurements, J. Geophys. Res., 110, D10S14, doi:10.1029/2004jd004874, 2005.

Omar, A. H., Winker, D. M., Kittaka, C., Vaughan, M. A., Liu, Z. Y., Hu, Y. X., Trepte, C. R., Rogers, R. R., Ferrare, R. A., Lee, K. P., Kuehn, R. E., and Hostetler, C. A.: The CALIPSO automated aerosol classification and lidar ratio selection algorithm, J. Atmos. Ocean. Tech., 26, 1994-2014, doi:10.1175/2009jtecha1231.1, 2009.

Omar, A. H., Liu, Z., Vaughan, M., Thornhill, K., Kittaka, C., Ismail, S., Hu, Y., Chen, G., Powell, K., Winker, D., Trepte, C., Winstead, E., and Anderson, B.: Extinction-to-backscatter ratios of Saharan dust layers derived from in situ measurements and CALIPSO overflights during NAMMA, J. Geophys. Res., 115, D24217, doi:10.1029/2010jd014223, 2010.

Oo, M. and Holz, R.: Improving the CALIOP aerosol optical depth using combined MODIS-CALIOP observations and CALIOP integrated attenuated total color ratio, J. Geophys. Res., 116, D14201, doi:10.1029/2010jd014894, 2011.

Ottaviani, M., Cairns, B., Chowdhary, J., Van Diedenhoven, B., Knobelspiesse, K., Hostetler, C., Ferrare, R., Burton, S., Hair, J., Obland, M. D., and Rogers, R.: Polarimetric retrievals of surface and cirrus clouds properties in the region affected by the Deepwater Horizon oil spill, Remote Sens. Environ., 121, 389-403, doi:10.1016/j.rse.2012.02.016, 2012.

Patadia, F., Kahn, R. A., Limbacher, J. A., Burton, S. P., Ferrare, R. A., Hostetler, C. A., and Hair, J. W.: Aerosol airmass type mapping over the urban Mexico City region from space-based multi-angle imaging, Atmos. Chem. Phys. Discuss., 13, 79317978, doi:10.5194/acpd-13-7931-2013, 2013.

Powell, K. A., Hostetler, C. A., Liu, Z. Y., Vaughan, M. A., Kuehn, R. E., Hunt, W. H., Lee, K. P., Trepte, C. R., Rogers, R. R., Young, S. A., and Winker, D. M.: CALIPSO lidar calibration algorithms. Part I: Nighttime 532-nm parallel channel 
and 532-nm perpendicular channel, J. Atmos. Ocean. Tech., 26, 2015-2033, doi:10.1175/2009jtecha1242.1, 2009.

Powell, K. A., Vaughan, M., Winker, D., Lee, K.-P., Pitts, M., Trepte, C., Detweiler, P., Hunt, W., Lambeth, J., Lucker, P., Murray, T., Hagolle, O., Lifermann, A., Faivre, M., Garnier, A., and Pelon, J.: Cloud-aerosol LIDAR Infrared Pathfinder Satellite Observations Data Management System Data Products Catalog, NASA Langley Research CenterDocument No: PC-SCI-503, NASA Langley Research Center, Hampton Virginia, available at: http://www-calipso.larc.nasa.gov/products/CALIPSO_DPC_ Rev3x4.pdf (last access: 21 May 2013), 22 December 2011.

Redemann, J., Zhang, Q., Livingston, J., Russell, P., Shinozuka, Y., Clarke, A., Johnson, R., and Levy, R.: Testing aerosol properties in MODIS Collection 4 and 5 using airborne sunphotometer observations in INTEX-B/MILAGRO, Atmos. Chem. Phys., 9, 8159-8172, doi:10.5194/acp-9-8159-2009, 2009.

Rogers, R. R., Hair, J. W., Hostetler, C. A., Ferrare, R. A., Obland, M. D., Cook, A. L., Harper, D. B., Burton, S. P., Shinozuka, Y., McNaughton, C. S., Clarke, A. D., Redemann, J., Russell, P. B., Livingston, J. M., and Kleinman, L. I.: NASA LaRC airborne high spectral resolution lidar aerosol measurements during MILAGRO: observations and validation, Atmos. Chem. Phys., 9, 4811-4826, doi:10.5194/acp-9-4811-2009, 2009.

Rogers, R. R., Hostetler, C. A., Hair, J. W., Ferrare, R. A., Liu, Z., Obland, M. D., Harper, D. B., Cook, A. L., Powell, K. A., Vaughan, M. A., and Winker, D. M.: Assessment of the CALIPSO Lidar $532 \mathrm{~nm}$ attenuated backscatter calibration using the NASA LaRC airborne High Spectral Resolution Lidar, Atmos. Chem. Phys., 11, 1295-1311, doi:10.5194/acp-11-12952011, 2011.

Rogers, R. R., Vaughan, M. A., Hostetler, C. A., Burton, S. P., Ferrare, R. A., Young, S. A., Hair, J. W., Obland, M. D., Harper, D. B., Cook, A. L., and Winker, D. M.: Looking Through the Haze: Evaluating the CALIPSO Level 2 Aerosol Layer Optical Depth using Airborne High Spectral Resolution Lidar Data, in preparation, 2013.

Sassen, K. and Wang, Z.: The clouds of the middle troposphere: composition, radiative impact, and global distribution, Surv. Geophys., 33, 677-691, doi:10.1007/s10712-011-9163-x, 2012.

Schuster, G. L., Vaughan, M., MacDonnell, D., Su, W., Winker, D., Dubovik, O., Lapyonok, T., and Trepte, C.: Comparison of CALIPSO aerosol optical depth retrievals to AERONET measurements, and a climatology for the lidar ratio of dust, Atmos. Chem. Phys., 12, 7431-7452, doi:10.5194/acp-12-7431-2012, 2012.

She, C. Y., Alvarez, R. J., Caldwell, L. M., and Krueger, D. A.: High-spectral-resolution Rayleigh-Mie lidar measurement of aerosol and atmospheric profiles, Opt. Lett., 17, 541-543, 1992.

Shimizu, A., Sugimoto, N., Matsui, I., Arao, K., Uno, I., Murayama, T., Kagawa, N., Aoki, K., Uchiyama, A., and Yamazaki, A.: Continuous observations of Asian dust and other aerosols by polarization lidars in China and Japan during ACE-Asia, J. Geophys. Res., 109, D19S17, doi:10.1029/2002jd003253, 2004.

Shipley, S. T., Tracy, D. H., Eloranta, E. W., Trauger, J. T., Sroga, J. T., Roesler, F. L., and Weinman, J. A.: High spectral resolution lidar to measure optical-scattering properties of atmospheric aerosols, 1. Theory and Instrumentation, Appl. Optics,
22, 3716-3724, 1983.

Sugimoto, N. and Lee, C. H.: Characteristics of dust aerosols inferred from lidar depolarization measurements at two wavelengths, Appl. Optics, 45, 7468-7474, 2006.

Sun, W., Liu, Z., Videen, G., Fu, Q., Muinonen, K., Winker, D. M., Lukashin, C., Jin, Z., Lin, B., and Huang, J.: For the depolarization of linearly polarized light by smoke particles, J. Quant. Spectrosc. Ra., 122, 233-237, doi:10.1016/j.jqsrt.2012.03.031, 2013.

Tesche, M., Ansmann, A., Müller, D., Althausen, D., Engelmann, R., Freudenthaler, V., and Groß, S.: Vertically resolved separation of dust and smoke over Cape Verde using multiwavelength Raman and polarization lidars during Saharan Mineral Dust Experiment 2008, J. Geophys. Res., 114, D13202, doi:10.1029/2009jd011862, 2009.

Vadrevu, K. P., Ellicott, E., Giglio, L., Badarinath, K. V. S., Vermote, E., Justice, C., and Lau, W. K. M.: Vegetation fires in the himalayan region - aerosol load, black carbon emissions and smoke plume heights, Atmos. Environ., 47, 241-251, doi:10.1016/j.atmosenv.2011.11.009, 2012.

Vaughan, M. A., Powell, K. A., Kuehn, R. E., Young, S. A., Winker, D. M., Hostetler, C. A., Hunt, W. H., Liu, Z. Y., McGill, M. J., and Getzewich, B. J.: Fully automated detection of cloud and aerosol layers in the CALIPSO lidar measurements, J. Atmos. Ocean. Tech., 26, 2034-2050, doi:10.1175/2009jtecha1228.1, 2009.

Warneke, C., Froyd, K. D., Brioude, J., Bahreini, R., Brock, C. A., Cozic, J., de Gouw, J. A., Fahey, D. W., Ferrare, R., Holloway, J. S., Middlebrook, A. M., Miller, L., Montzka, S., Schwarz, J. P., Sodemann, H., Spackman, J. R., and Stohl, A.: An important contribution to springtime Arctic aerosol from biomass burning in Russia, Geophys. Res. Lett., 37, L01801, doi:10.1029/2009g1041816, 2010.

Winker, D. M., Hunt, W. H., and McGill, M. J.: Initial performance assessment of CALIOP, Geophys. Res. Lett., 34, L19803, doi:10.1029/2007g1030135, 2007.

Winker, D. M., Vaughan, M. A., Omar, A., Hu, Y. X., Powell, K. A., Liu, Z. Y., Hunt, W. H., and Young, S. A.: Overview of the CALIPSO mission and CALIOP data processing algorithms, J. Atmos. Ocean. Tech., 26, 2310-2323, doi:10.1175/2009jtecha1281.1, 2009.

Winker, D. M., Tackett, J. L., Getzewich, B. J., Liu, Z., Vaughan, M. A., and Rogers, R. R.: The global 3-D distribution of tropospheric aerosols as characterized by CALIOP, Atmos. Chem. Phys., 13, 3345-3361, doi:10.5194/acp-13-3345-2013, 2013.

Yang, W., Marshak, A., Várnai, T., Kalashnikova, O. V., and Kostinski, A. B.: CALIPSO observations of transatlantic dust: vertical stratification and effect of clouds, Atmos. Chem. Phys., 12, 11339-11354, doi:10.5194/acp-12-11339-2012, 2012.

Young, S. A. and Vaughan, M. A.: The retrieval of profiles of particulate extinction from Cloud-Aerosol Lidar Infrared Pathfinder Satellite Observations (CALIPSO) data: algorithm description, J. Atmos. Ocean. Tech., 26, 1105-1119, doi:10.1175/2008JTECHA1221.1, 2009.

Yu, H. B., Chin, M., Winker, D. M., Omar, A. H., Liu, Z. Y., Kittaka, C., and Diehl, T.: Global view of aerosol vertical distributions from CALIPSO lidar measurements and GOCART simulations: regional and seasonal variations, J. Geophys. Res.-Atmos., 115, D00h30, doi:10.1029/2009jd013364, 2010. 
Zaveri, R. A., Shaw, W. J., Cziczo, D. J., Schmid, B., Ferrare, R. A., Alexander, M. L., Alexandrov, M., Alvarez, R. J., Arnott, W. P., Atkinson, D. B., Baidar, S., Banta, R. M., Barnard, J. C., Beranek, J., Berg, L. K., Brechtel, F., Brewer, W. A., Cahill, J. F., Cairns, B., Cappa, C. D., Chand, D., China, S., Comstock, J. M., Dubey, M. K., Easter, R. C., Erickson, M. H., Fast, J. D., Floerchinger, C., Flowers, B. A., Fortner, E., Gaffney, J. S., Gilles, M. K., Gorkowski, K., Gustafson, W. I., Gyawali, M., Hair, J., Hardesty, R. M., Harworth, J. W., Herndon, S., Hiranuma, N., Hostetler, C., Hubbe, J. M., Jayne, J. T., Jeong, H., Jobson, B. T., Kassianov, E. I., Kleinman, L. I., Kluzek, C., Knighton, B., Kolesar, K. R., Kuang, C., Kubátová, A., Langford, A. O., Laskin, A., Laulainen, N., Marchbanks, R. D., Mazzoleni, C., Mei, F., Moffet, R. C., Nelson, D., Obland, M. D., Oetjen, H., Onasch, T. B., Ortega, I., Ottaviani, M., Pekour, M., Prather, K. A., Radney, J. G., Rogers, R. R., Sandberg, S. P., Sedlacek, A., Senff, C. J., Senum, G., Setyan, A., Shilling, J. E., Shrivastava, M., Song, C., Springston, S. R., Subramanian, R., Suski, K., Tomlinson, J., Volkamer, R., Wallace, H. W., Wang, J., Weickmann, A. M., Worsnop, D. R., Yu, X.-Y., Zelenyuk, A., and Zhang, Q.: Overview of the 2010 Carbonaceous Aerosols and Radiative Effects Study (CARES), Atmos. Chem. Phys., 12, 7647-7687, doi:10.5194/acp-12-7647-2012, 2012.
Zhang, J., Campbell, J. R., Reid, J. S., Westphal, D. L., Baker, N. L., Campbell, W. F., and Hyer, E. J.: Evaluating the impact of assimilating CALIOP-derived aerosol extinction profiles on a global mass transport model, Geophys. Res. Lett., 38, L14801, doi:10.1029/2011g1047737, 2011. 